\title{
TARI SANGHYANG: MEDIA KOMUNIKASI SPIRITUAL MANUSA DENGAN ROH
}

\author{
I Nyoman Lodra \\ Arts and Crafts Education, Faculty of Languages and Arts, \\ Universitas Negeri Surabaya, Jawa Timur, Indonesia \\ n.lodra@yahoo.co.id \\ Artikel diterima 24 Maret, diseleksi 17 Mei, dan disetujui 19 Oktober 2017
}

\begin{abstract}
This paper scrutinizes the Dance of Sanghyang which includes trance as a medium of mystical communication between human and spirits. In addition to entertainment, the dance is conducted to present spirits into the body of the dancer. The questions are: 1) what is the procession to present the spirits to the body of the dancer? 2) what is the form of the mystical communication of human and the spirits within the body of the dancer? 3) what is the existence of the Dance of Sangyang in global era Bali? The research aims at 1) describing the procession of the presentation of the spirits in the body of the dancer; 2) portraying the form of mystical communication of human and the spirits; and 3) identifying the existence of the Dance of Sanghyang in global era Bali. The benefit of the research is 1) to know the procession of the presentation of the spirits in the body of the dancer; 2) to identify the form of mystical communication of human and the spirits; and 3) to discover the existence of the Dance of Sanghyang in global era Bali. The research is conducted through qualitative-descriptive method. The data is collected from observation, interviews, and documentation. The discussion within the paper encompasses ethnography, social exchange theory, and hegemony theory. The author argues that presenting the spirit is conducted by preparing several equipment such as offerings, spells, music. The mystical communication takes the form of verbal and oral model. The dance is now hardly found in Bali. Last but not least, the presentation of the spirits is needed to overcome life problems in Bali.
\end{abstract}

Keywords: Dance, Sanghyang, Spirit, Trance, Spiritual Communication.

\section{Abstrak}

Artikel ini mengkaji dan menganalisis "Tari Sanghyang" terkait dengan "kerauhan" (trance), sebagai media komunikasi spritual antara manusia dengan roh. Tarian tersebut selain untuk hiburan juga untuk mendatangkan roh masuk ke dalam tubuh penari. Permasalahan: 1). bagaimana prosesi mendatangkan roh masuk ke dalam tubuh penari sangyang? 2). bagaimana bentuk komunikasi spritual manusia dengan roh dalam tubuh penari? 3) bagaimana eksistensi tari sanghyang pada eraglobal di Bali. Tujuan penelitian; (1) mendiskripsikan prosesi mendatangkan roh masuk ke dalam tubuh penari sangyang, (2) mendeskripsikan bentuk komunikasi spritual manusia dengan roh. (3) mengetahui keberadaan tari sanghyang pada eraglobal di Bali. Manfaat: (1) tahu cara-cara mendatangkan roh masuk ke tubuh penari sangyang, (2) mengetahui bentuk komunikasi spiritual manusia dengan roh. (3) mengetahui keberadaan tari sanghyang pada eraglobal di Bali. Penelitian dengan pendekatan metode kualitatif deskriptif, pengambilan data: observasi, wawancara, dan dokumen. Teori pembahas dengan etnografi, pertukaran sosial, dan hegomoni. Temuan; mendatangkan roh dengan perlengkapan sesaji, mantra, musik, dan komunikasinya dalam bentuk verbal, lisan serta tarian tersebut mulai langka di Bali. Temuan lainnya di eraglobal manusia masih membutuhkan kehadiran roh untuk mengatasi persoalan hidup masyarakat di Bali.

Kata kunci: Tari, Sanghyang, Roh, Kerauhan, Komunikasi Spiritual. 


\section{PENDAHULUAN}

"Dreste", "desa kalapatre",
"desa mawecare" sebagai sikap, pemikiran yang dihargai, dijunjung tinggi, dan dihargai oleh masyarakat di Bali. Pemaknaan budaya lokal tersebut menjadi prinsip kehidupan bermasyarakat terimplementasi dalam bentuk menghargai konsep, pikiran, prilaku masyarakat yang beragam. Hetrogenitas masyarakat dibingkai nilai budaya tersebut menjadi landasan mewujudkan masyarakat yang bertolrensi berujung pada kedamaian, kerukunan, dan ketertiban masyarakat di Bali. Masyarakat di Bali bersifat pluralis dan dinamis dalam "bingkai" agama Hindu, diperkuat dengan landasan hidup yakni "hukum karmapala". Implementasi dari "hukum karmapala", jika berbuat baik hasil yang akan mereka terima diyakini baik, sebaliknya perbuatan buruk yang diterima akan buruk pula. Kedua nilai budaya tersebut mampu menjaga kedamaian, keharmonisan, kerukunan kehidupan masyarakat Bali yang pluralis dan majemuk dan mampu mendorong tumbuh kembang keanekaragaman budaya dan kesenian di Bali seperti halnya "Tari Sanghyang".

“Tari Sanghyang" adalahjenis tarian sakral sarat dengan nilai-nilai ajaran spritual prasejarah seperti keyakinan, kepercayaan, dikemas bentuk kesenian diperuntukan dalam ritual pemujaan dan kegiatan upacara agama Hindu. Kemasan bentuk kesenian di sesuaikan kondisi lingkungan geografis, adat, sosial dan budaya. Secara visual pada saat tertentu penarinya dalam keadaan tidak sadar (trace), sikap, prilaku diluar logika, tidak rasional, tetapi masih bisa berkomunikasi verbal dengan lingkungan. Dalam keadaan tersebut penari dikendalikan oleh kekuatan "roh" yang ada dalam tubuhnya. Judith Lynne (1987) dalam To Dance is Human: A Theory of Nonverbal Communicatio, disebutkan dalam tarian keadaantidaksadar(trace) ada komunikasi dalam bentuk tanda atau bahasa isyarat. Seperti halnya "Tari Sanghyang" bagian dari unsur budaya prasejarah oleh masyarakat Bali di pentaskan di "pura" atau ditempat lain dengan tujuan membebaskan masyarakat dari pengaruh kekuatan jahat "keberebehan". Merunut Edward Burnett Tylor, dalam Koentjaraningrat, (1997) budaya tersebut sulit dipahami, bentuknya rumit, komplek, terkandung kesenian, moral, adat-istiadat, kepercayaan, keyakinan diterima masyarakat.

"Tari Sanghyang" berkembang di beberapa daerah seperti di daerah Bangli, Gianyar, Karangasem, Buleleng, Jemberana, Tabanan, dan Klungkung. Oleh Ardana dalam Sutaba (2007: 13) keberadaan kesenian tersebut penanda masyarakat Bali meyakini ada sifat-sifat roh yang bisa membantu kehidupan manusia. Menurut Sri-Srmad A.C. Bhaktivedanta Swami Prbhupada (Bhagavad Gita, 99) menjelaskan sifat roh, seperti berikut:

Tidak ada kelahiran maupun kematian bagi sang roh pada saat manapun. Dia tidak diciptakan pada masa lampau, tidak diciptakan masa sekarang dan tidak diciptakan pada masa yang akan datang. Tidak dilahirkan, berada untuk selamanya dan bersifat abadi dan tidak terbunuh apabila badannya terbunuh.

Sifat-sifat roh tidak dapat dipatahkan, tidak dapat dilarutkan, dibakar, dipindahkan, dan ada dimanamana.

Sifat-sifat roh tersebut menurut Mangku Pande (55 tahun) dari Denpasar Bali yang dikenal sebagai "pawang roh", menceritakan "roh" itu bisa marah, menyakiti, menggangu, jahat, kuat, dan kadangkala baik membantu kesusahan manusia. Misalnya, roh merasa terganggu 
kenyamanannya karena tempat tinggal dipakai untuk kegiatan atau aktivitas tanpa "pemberitahuan sebelumnya" mereka bisa marah dan menggangu manusia. Seperti terjadi di salahsatu SMK swata di Gianyar, siswa/siswi di kerauhan (trace), masal usai menari dalam rangka merayakan ulang tahun sekolah. Siswa/ siswi yang kerauhan (trace), tanpa sadar dengan sangat aktraktif mata terpejam "ngamuk" merusak pasilitas sekolah. Menurut Mangku Pande, siswa/siswi tersebut tubuhnya sudah kemasukan "roh" yang sudah marah oleh karena tempat tinggal sudah bising dan mereka merasa terganggu (gianyar, 24, November, 2014). Mangku Pande melakukan 'komunikasi spritual" atau berdialog dengan "roh" yang masuk dalam tubuh siswa/siswi penari dengan perantara "sesaji". Komunikasi antara Mangku pande dengan roh pada intinya ada beberapa kesepatan dan beberapa menit kemudian siswa/siswi kembali sadar, normal seperti sediakala. Menurut pengakuan siswa/siswi yang tadi "kerauhan" mengaku tidak tahu apa yang telah mereka perbuat.

Penulis mengutif beberapa point isi komunikasi spiritual antara mangku pande dengan "roh" sebagai berikut:

metangi sire nii wenten ring manuse, napi wenten kobetan, ring dije megenah, tetujon iring bawosan. Sampunan ngaruggade, mangkin megingsir saking wadang manusene rereh genah sane leanan, mangkin napi sane katuran? (...... bangun siapa yang ada dalam tubuh ini, apa yang menjadi keberatan, tinggal dimana, apa yang menjadi tujuan mari kita bicarakan. Jangan mengganggu, sekarang pergi dari tubuh manusia ini cari tempat lain, sekarang apa yang minta?) Sebelum komunikasi pawang roh (pemangku) menyiapkan sajen, air putih, dan jenis lainnya (wawancara, tgl 23 November, 2014).

Masyarakat di Bali pada umumnya paham "roh" dan "atman" yang bersemayam dalam tubuh manusia membuat orang bisa hidup, "kerauhan" (trace) atau sakit. Kedua unsur tersebut memiliki sifat-sifat berbeda, seperti dijelaskan oleh Sri-Srmad A.C.bhaktivedanta Swami Prbhupada (Bhagavad Gita, 99) "roh" memiliki sifatsifat tidak mengalami kelahiran, kematian, bersifat abadi, tidak terbunuh. Sedangkan "atman" merupakan percikan Tuhan, dia tidak terikat, tidak berbentuk, yang menjadikan manusia hidup. Jika "atman" lepas dari tubuh manusia menyebabkan manusia mati. Atman meninggalkan dalam tubuh dalam bentuk roh telah terkontaminasi oleh "pancamahabhuta". Roh memiliki sifat jahat, baik, berada dalam tubuh manusia karena di undang atau masuk dengan sendirinya. "Atman" dan "roh" memiliki kesamaan bersifat abadi, tidak mati, tidak lahir, tidak tampak ada dalam tubuh manusia. Nilai budaya tersebut bagian dari peradaban manusia prasejarah (animisme, dinamisme, dan totemisme). "Roh" nenek moyang yang telah meninggal dunia, diyakini masih memperhatikan dan melindungi kehidupan mereka. Sejalan dengan pikiran Marte Kristin (2004) dalam "Dancing on Holy Ground. Embodied Expressions" menyebut sebagai tarian suci.

Fenomena-fenomena tersebut sebagai ciri ada nilai budaya prasejarah, bali kuno, Hindu yang berkembang di eraglobal, seperti "tari sanghyang" di Bali. Hal yang sama dipikirkan oleh May Britt (2005) dalam metode kualitativ dalam fenomenologi etnografi sebagai sebuah kasusitas, mungkin tidak banyak ditemukan di daerah lain. Begitu juga dikatakan Anya Peterson (2002) dalam The Antropology of Dace, sebagai suatu hal yang sudah jarang ditemukan namun eksistensi 
masih tetap ada di masyarakat. Seperti halnya "tari sanghyang" sudah jarang dipentaskan bahkan dibeberapa daerah sudah tidak aktif lagi (hilang). Penelitian ini menjadi penting di lakukan dengan untuk penyelamatan sebuah identitas budaya dengan judul "Tari Sanghyang": komunikasi spiritual manusia dengan roh. Tujuan merekonstruksi kembali nilainilai komunikasi spritual tersebut agar bisa diwarisi dan dipelajari masyarakat luas.

\section{PEMBAHASAN}

\section{Roh sebagai Peradaban Prasejarah}

Keberadaan roh sebagai bentuk peradaban prasejarah masyarakat etnis Bali sebagai pertanda adanya tatanan hidup bermasyarakat yang baik dan teratur. Benda sarcofagus (peti mati) temuan benda arkeologi berhias topeng, cecak, dan goresan lainnya di daerah Sembiran Buleleng, Gianyar, dan Gilimanuk pertanda sama menunjukan peradaban yang sudah teratur. Hal tersebut diperkuat oleh Soejono (1977) bahwa situs Gilimanuk ada pola penguburan tanpa wadah bersifat sekender maupun primer, dan juga kuburan dengan tempayan (priyuk gerabah) selain sarkofagus. (kompasiana. com/dodichandra/sarkofagus-dankepercayaan-masyarakat-bali). Motif tersebut bersifat simbolis dimaksudkan sebagai tanda penghormatan pada roh leluhur yang meninggal dunia. Teknik pembuatan dengan cara dipahat, dibobok, dan diperkirakan dikerjakan oleh banyak orang (gotongroyong). Para ahli memperkirakan benda kubur tersebut menunjukan ada klasifikasi status sosial di masyarakat Bali Kuno. Motif- pada dinding sarcofagus membuktikan manusia prasejarah di Bali telah mengenal kehidupan bermasyarakat dengan baik. Disamping itu para ahli juga menyimpulkan masyarakat adanya kepercayaan dan kegiatan prosesi ritual hal tersebut ditandai dengan adanya motif dan perangkat ritual. Diperirakan kepercayaan, keyakinan tersebut menjadi landasan dalam tumbuh kembangnya agama Hindu di Bali.

Masyarakat prasejarah di Bali meyakinkan "roh" bisa memberikan keselamatan dan kesejahteraan hidup (Sutaba, 1980: 35, dalam Ardana, 2007: 13). Sama dengan pemikiran Karen Armstrong dalam bukunya yang berjudul" The Great Transformation" (1977) manusia sebagai subjek dalam segala aktivitas dalam pelaksanaan ajaran agama ketergantungan pada bendabenda simbolis. Dengan demikian roh yang bersifat abstrak sebagai bentuk peradaban manusia prasejarah.

\section{“Roh" dalam Pemahaman Hindu}

Keyakinan dan kepercayaan pada roh berkembang di masa bali kuno yang diyakini mampu melindungi manusia dari pengaruh kekuatan jahat atau ancaman magis lainnya. Masa ini berlanjut dengan masuk pengaruh sektesekte dari India. Masyarakat etnis Bali menerima kehadiran sekte-sekte dan hidup berdampingan dengan damai ditandai dengan ketertiban beragama. Masa ini ditandai dengan terhegomoni masyarakat hindu oleh keyakinan dan kepercayaan pada kekuatan para "dewa" selain adanya roh. Kekuatan baru tersebut diyakini menyamai kekuatan roh. Ada akulturasi dari kedua budaya yang mewarnai masa bali kuno sebagai bentuk pengkayaan budaya sebelumnya. Beberapa sekte yang berkembang seperti sekte Sambu, Brama, Indra, Wisnu, Siwa, Bayu, dan Baierawa. Oleh Dipayana (2010: 13) akulturasi budaya tersebut dicatat sebagai Indianisasi di masa bali kuno. Kedatangan Rsi Markandya dan pengikutnya dari Jawa terlebih dahulu melakukan upacara suci sejenis 
"pecaruan" disekitar gunung Agung (toh Langkir) untuk tujuan keselamatan selama mereka ada di Bali. Upacara suci pencaruan tersebut menandakan beliau juga menghormati keberadaan roh yang ada disekitarnya. Kedatangan beliau berkontribusi pada penyempurnaan kehidupan beragama yang ditandai dikenalnya tempat pemujaan "kayangan tiga" dan sistem persubakan (https://dwimistyriver.word press. com/2010/08/31/ dharmayatra-maharsimarkandeya).

Begitu juga dalam kesenian untuk sebuah ritual, terkait dengan keberadaan "roh". Masa hindu ini tumbuh kembang beragam kesenian ritual tersebut seperti "Tari Sanghyang". Pada kesenian tersebut roh menjadi penting yang membuat penarinya "kerauhan" (trace) dan berkembang subur di masa peradaban Hindu. Agama Hindu mulai diajarkan dengan tertib mengedepankan dan menghargai nilai-nilai budaya sebelumnya. Agama Hindu berkembang di Bali pada masa berikutnya merupakan bentuk panduan dari adanya keyakinan, kepercayaan pada roh dan dewa-dewi.

\section{Kajian Tari Sanghyang}

Tarian Sanghyang merupakan tarian sakral yang berkembang di Bali yang tidak dipertotonkan tetapi diselenggarakan dalam rangkaianupacara atau sejenis ritual dan penarinya dalam kondisi "kerauhan"(trace). Di Bali ada beberapa jenis tari snghyang diantaranya: Tari Sanghyang dedari, sanghayang deling, sanghyang dangkluk, sanghyang penyalin, sanghyang celeng, sanghyang medi, sanghyang bumbung, sanghyang kidang, sanghyang jenger, sanghyang sengkrong, dan sanghyang jaran. Secara umum jenis Tari Sanghyang ini memiliki fungsi yang sama, yaitu untuk mengusir roh jahat atau kekuatan magic, hanya yang membedakan bentuk pertunjukan dan busana yang dipakai. Secara khusus kostum yang dipakai disesuaikan dengan jenis tari sanghyangnya. Seperti halnya Tari sanhyang dedari jenis tarian yang dibawakan oleh satu atau dua orang gadis kecil. Para ahli memperkirakan asal mula tarian Sanghyang dari Desa Bona Gianyar. Tarian ini muncul berawal dari terjadinya wabah cacar yang sangat hebat dan hampir semua masyarakat terserang. Tarian ini dengan iringan instrumen dan vokal berlaraskan Slendro serta pelog. Beberapa sumber menyebutkan Tari sanghyang merupakan sisa-sisa peradaban pra-Hindu terus berkembang samapai masa eraglobal.

Masing-masing daerah di Bali memiliki catatan terkait "Tari Sangyang “, seperti desa Bona, Gianyar. Pementasan tarian ini diawali adanya wabah penyakit menimpa desa Bona yang sulit disembuhkan. Menurut beberapa tokoh masyarakat pada saat "odalan" dipelataran pura anak-anak perempuan umunya belasan tahun sedang bermain "kerauhan" (trace). Anak-anak tersebut terus menari sambil memberi petunjukpetunjuk "mebaosan" (bicara) agar masyarakat melakukan sesuatu. Dalam prosesinya tarian ini dipandu oleh beberapa orang mengelilingi pura. Jika sudah cukup atau selesai tubuh penarinya akan roboh dan pingsan menandakan roh sudah meninggalkan tubuh mereka, pada saat itu "pemangku" memercikan "tirta" (air suci), saat itu penari akan sadar kembali. Penarinya anak gadis muda belia kemudian masyarakat menyebut dengan tari sanhyang "Dedari".

Persyaratan Tari Sanghyang yang ditarikan oleh kaum laki, perempuan dan penarinya tidak membutuhkan ketrampilan menari, cantik, ganteng, terpenting terbebas dari perbuatan jahat, berbohong, berzina dan sejenisnya jasmani (suci). Jika sedang "kerauhan" (trace) berprilaku diluar logika manusia, seperti: menari dalam kobaran api, 
menari dan menginjak-injak bara api, memanjat batang bambu, memakan beling, melompat-lompat meringik meniru gerakan binatang. Prilaku tersebut sesuai dengan karakteristik roh yang masuk ke dalam tubuh mereka. Tari Sanghyang dipentaskan biasanya terkait dengan masalah kondisi masyarakat sedang mengalami musibah, seperti "kegeringan". Jenis tari ini ditarikan dengan tujuan mengusir wabah penyakit, yang disebabkan oleh rohjahat. Jika penari sudah "kerauhan" (trace) tidak sadarkan diri, mata terpejam, melompat-lompat, menari, memanjat batang bambu, dan ada yang kebal dengan tusukan senjata tajam. Konsep kesenian tersebut sejalan dengan pemikiran David (2011) dimana proses dimulai dengan melakukan meditasi dan ritual-ritual agama sehingga muncul rasa estetik seperti halnya dalam tarian sanghyang.

Tujuan utama pementasan "Tari sanghyang" untuk dimintai pertolongan mengatasi kesusahan masyarakat. Masyarakat terhegomoni semua perintah, petunjuk disetujui oleh seluruh anggota masyarakat yang ada disekitarnya (pemangku, kepala adat). Dengan segala kesadaran mereka sudah ada dalam kekuasaan roh yang ada ditubuh penari. Oleh Gramci (dalam Sugiono, 1999:31) tidak lagi menginternalisasi nilai-nilai penguasaan dan mereka menyetujui serta terjadi subordinasi atau disebut sebagai "hegomoni". Dalam tarian tersebut terjadi "hegomoni" roh terhadap manusia. Selain berfungsi untuk mengusir wabah penyakit dan kekuatan magic oleh masyarakat melakukan dialog atau komunikasi spritual alam gaib Tarian digunakan oleh masyarakat untuk melakukan komunikasi dengan roh yang ada dalam tubuh penari meminta agar dijauhakan dari segala bahaya. Dialog antara roh dengan manusia ini penulis sebut dengan komunikasi spiritual. Oleh Judith Lynne (1987) dalam tarian dan manusia, termasuk tarian sangyang terjadi bentuk komunikasi verbal dikatakan sebagai hegomoni massa.

Prosesi ritual pementasan tari sangyang diadakan pada malam hari dengan beberapa tahapan-tahapan yang tidak boleh dilanggar. Tampak pada gambar jenis tari sanghyang Jaran dan tari ganghyang Dedari.

\section{Gb. 1.a,Tarian Sanyang Jaran}

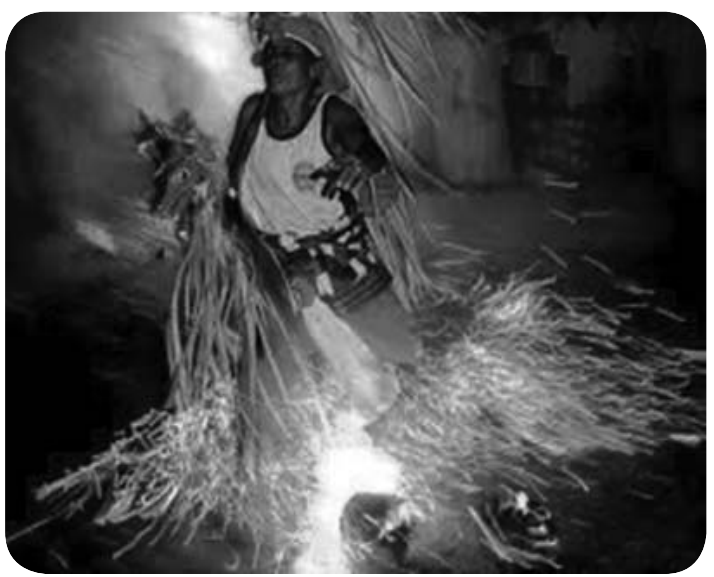

Gb. 1.b,Tarian Sanyang Jaran

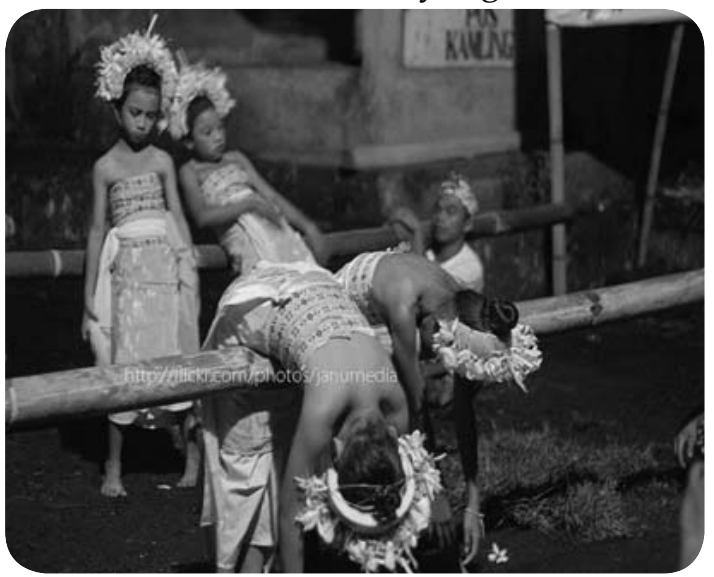

Sumber (https://id.wikipedia.org/wiki/ Sanghyang) ( https://id.wikipedia.org/ wiki/Sanghyang

Kedua jenis tari sanghyang tersebut di atas, berkembang di zaman Hindu sampai di eraglobal bercirikan nilai-nilai peradaban prasejarah, dan bali kuno. Kesenian ini tumbuh kembang ditengahtengah masyarakat tradisi di Bali seperti; di desa Bona, desa Batubulan, Gianyar, desa Batur, Bangli, Buleleng, Tabanan. Jenis kesenian tersebut tidak bisa 
tonton sewaktu-waktu, seperti layaknya kesenian lain.

\section{Struktur Pementasan}

Pementasan jenis-jenis tari
sanghyang (sanghyang Dedari,
sanghyang Deling, sanghyang Bojog,
sanghyang Jaran, sanghyang Sampat
dan sanghyang Celeng) secara struktur
dapat dipilah menjadi beberapa langkah-
langkah seperti berikut.

1. Pemuka masyarakat; pengurus adat, pemangku mempersiapkan sesaji, api, air, dan orang pilihan dilaksanakan pada malam hari bersama-sama melakukan doa pemujaan.

2. Orang-orang pilihan bersemedi diiringi dengan japa mantra, nyannyian suci, suara gambelan saron, semarpegulingan dengan tujuan menundang kedatangan roh untuk masuk dalam tubuh.

3. Biasanya orang pilihan ada yang sudah mengenakan pakaian, busana, sesuai dengan jenis tari sanghyang.

4. Roh masuk dalam tubuh menjadikan "kerauhan" ditandai tubuhnya ambruk, bergetar, berteriak-teriak, bergerak langsung masuk ke api yang telah disiapkan.

5. Tarian ini berahir ketika roh telah meninggalkan tubuh dan penarinya akan ambruk, tidak sadarkan diri kembali normmal seperti sediakala.

Tari Sanghyang sebagai tari wali sudah ada pada peradaban prahindu. Di eraglobal tarian ini sudah jarang dipentaskan, beberapa hasil penelitian jenis kesenian ini jumlahnya masih sekitar 20 jenis tersebar di beberapa desa di Bali.

\section{Penggeseran Struktur Pementasan}

Di tahun 80-an kesenian tersebut tidak lagi hanya dapat lihat di pura tetapi bisa ditonton di tempat hiburan lain yang disuguhkan untuk wisatawan. Di beberapa desa seperti di Bona, tari sanghyang sudah dimodifikasidipadukan dengan tarian Cak. Masyarakat tidak lagi mempertimbangkan nilai kesakralan terpenting bisa dijual mendatangkan keuntungan. Penari dalam kondisi "kerauhan" (trance) mereka menari yang disertai dengan nyanyian, dan suara gambelan. Gerakan penari yang dinamis, kadang lembut, keras dan menari kadang di atas bara api, masuk dalam kobaran api, dan dipentaskan di malam hari. Pada struktur pementasan terjadi penggeseran seperti halnya; durasi waktu pementasan sudah diatur oleh pengelola hiburan, pementasan tempat-tempat hiburan. Dengan penggeseran stuktur tersebut berdampak pada perubahan bentuk, fungsi, dan makna., hal ini disesuaikan pada kepentingan industri pariwisata. oleh Yasraf (2015) disebutkan sebagai medan kreatif didukung oleh medan ekspresi dengan ide-ide baru atau inovasi, dilanjutkan dengan produksi sesuai kebutuhan konsumen (wisman-wisnu).

Fungsi awal tari sanghyang untuk mengusir roh jahat, melindungi masyarakat dari ancaman kekuatan gaib, pada kemasan industri pariwisata bersifat menghibur. Penggeseran fungsi secara langsung pada makna dari sifat sakral ke sekuler. Oleh Appadurai (dalam Ritzer dan Douglas, 2007) mengartikan sebagai pengaruh dari budaya global, adanya pergerakan uang (finascape) dan ideologi (ideoscape). Dalam kajian sosiologi dalam kesenian tersebut telah terjadi perubahan sosial, termasuk pola hubungan pelaku industri pariwisata dengan kelompok/ masyarakat. Sebagaiman dikatakan Emile Durkheim, sebagai fakta sosial yang ada dalam masing-masing individu di masyarakat. Sejalan dengan Peter 
L. berger, adanya hubungan antara individu dan masyarakat (George Ritzer dan Douglas Goodman, 2009). Kajian sosiologi dapat mengungkap proses penggeseran struktur pementasan seperti halnya dalam tari sanghyang, seperti pementasan di Desa Bono, Gianyar, Batubulan, dan lainnya. Penggeseran struktur pementasan tari sanghyang disisi lain sebagai usaha penyelamatan, pelestarian kesenian yang mulai redup dan mulai langka.

Secara etnografi kesenian "kerauhan" ini menunjukan adanya penggeseran dalam kehidupan masyarakat Bali. Mereka berintraksi dengan lingkungan sosial, ekonomi global, budaya global yang yang melekat dalam wisatawan. Hal ini membawa penggeseran dari sosial religius, magis, menjadi profit orented, komersial. Lodra (2015) mengatakan industri pariwisata menyebabkan adanya komudifikasi dari berbagai aspek keagamaan, yang memunculkan konplik. Pendapat ini didukung oleh Burn and Holden (1995) yang melihat perubahan fungsi kebudayaan, karena kebudayaan di pandang sebagai sumber daya komersial. Dampak pariwisata terhadap masyarakat / kebudayaan setempat, harus disadari bahwa kebudayaan adalah sesuatu yang secara internal terdeferensiasi, aktif, dan selalu berubah. Oleh Michel Picard (1996) disebut sebagai proses turistifikasi. Pada konsekuensi dibawa pariwisata bukan saja menyebabkan terjadi penggeseran, tetapi dimaknai sebagai penyelamatan nilai budaya dan memberi kesejahteraan pada masyarakat pendukungnya.

\section{Penggeseran Bentuk}

Industri pariwisata menyebabkan terjadi penggeseran bentuk tari sanghyang, sebelumnya busana atau asisoris dikenakan seadanya. Begitu juga tempat dan waktu pementasan di "pura" atau ditempat lainnya terkait dengan ritual, atau pada saat upacara "odalan". Lama pementasan tidak bisa ditentukan, tergantung pada penari yang sudah kemasukan "roh", jika dipandang cukup tarian penarinya sadar, tarian ini sudah selesai. Sesudah dikemas dalam untuk kebutuhan industri pariwisata busana atau asisoris yang dikenakan sangat indah di hias agar lebih menarik, Tempat pementasan sudah masuk ditempattempat hiburan seperti di hotel atau di stid-stid lainnya. Begitu pula waktu pementasan kesenian ini durasi waktunya diatur oleh manajemen pertunjukan.

\section{Penggeseran Fungsi}

Tari Sanghyang awalnya muncul untuk kepentingan mengusir roh jahat, memiliki kekuatan gaib mengancam suatu desa di Bali. Dengan kenyakinan dan kepercayaan masyarakat setelah pementasan kesenian sakral tersebut desa terbebas dari wabah penyakit atau ancaman dari roh jahat. Masuknya industri pariwisata kemasan kepentingan pementasan sudah mulai bergeser untuk mengbur.

\section{Penggeseran Makna}

Makna diartikan sebagai simpulan dari suatu kata bertautan antara benda dengan peristiwa atau keadaan tertentu bersifat subjektif memiliki ruang yang begitu luas. Seperti halnya kesenian yang berkembang di Bali ada bersifat sakral dan sekuler. Sifat sakral oleh penduduk lokal bisa dimaknai sebagai sesuatu terkait dengan agama, ritual, magis, dan sejenisnya. Begitu pula dengan sifat sekuler lebih cendrung dengan nilai industri, ekonomis, dan komersial. Dengan demikian makna sifatnya subjektif bisa saja sebagai "lebel" melekat pada benda atau pada peristiwa. 
Tari Sanghyang sebagai wujud jenis tarian yang bersifat sakral bernilai magis, estetis, mempresentasikan bercirikan dari berbagai peradaban, seperti nilai prasejarah, Bali Kuno, dan zaman Hindu. Nilai-nilai peradaban tersebut menyatu dalam bentuk tarian dilandasi dengan keyakinan adanya "roh", kepercayaan adanya kekuatan magis, dan nilai agama Hindu dengan pementasan bertujuan untuk memohon keselamatan, mengusir wabah penyakit, dan terhidar dari bencana alam. Kesenian yang berkembang di zaman Hindu dengan berbagai jenis dan bentuknya seperti Sanghyang Dedari, Sanghyangh Deling, Sanghyang Memedi, Sanghyang Jaran, Sanghyang Celeng, dan sejenisnya. Semua jenis tarian sanghyang tersebut di awali dengan upacara atau ritual, disertai dengan nyanyian, gambelan, atau kidung-kidung suci setelah itu penarinya pingsan tidak sadarkan diri sebagai pertanda masunyan roh.

Pada tahun 70-an jenis tarian tersebut cukup pepoler oleh karena sering dipentaskan di tempat hiburan dengan tujuan komersial. Kemasan Tari Sanghyang mulai bergeser, awalnya dipentaskan karena dibutuhkan untuk mengusir wabah penyakit atau tujuantujuan magis lainnya, kemudian mulai di tahun 70-an di dorong oleh industri pariwisata berubah pementasannya untuk menghibur wisatawan dan mendapatkan keuntungan material. Perkembangan industri pariwisata ada dibalik pergeseran tujuan semula tarian tersebut. Oleh Dharsono (1999: 130) penggeseran tersebut di atas sebagai art of by touristme atau seni untuk pariwisata. Budaya art of by touristme dan art of acculturation dalam bentuk tiruan, miniatur, tidak sakral sarat dengan kepentingan ekonomi (kapitalis). Oleh Stephan Bongard (2010) dalam bukunya "shall we dace? hal tersebut dalam ekplorasi tarian dirasakan pada kesejahteraan. Bagaimanapun industri pariwisata berperan dalam pelestarian kesenian ini walaupun menampakan perubahan sosial, ekonomi, budaya, dan telah terjadi penggeseran makna dari tari sanghyang. Pada eraglobal seperti sekarang ini pementasan Tari Sanghyang bersifat sakral atau sekuler mulai redup, mungkin juga suatu saat nanti anak cucu kita akan kehilangan jejak. Semua hal tersebut jelas ada faktor-faktor peyebab yang perlu untuk dilakukan penelitian yang lebih mendalam.

\section{Kehilangan Jejak Tari Sanghyang}

Tari Sanghyang sudah ada ratusan tahun lalu tumbuh kembang bersamaan dengan masuknya peradaban hindu ke Bali. Keyakinan, kepercayaan, pada roh, dewa-dewi, dalam kegiatan ritual, upacara "odalan" kesenian tersebut dipentaskan. Pada prosesi ritual pementasan penari dalam kondisi dengan "kerauhan" (trace). Belakangan kesenian sakral ini kehilangan "famor" dan jarang dipentaskan. Secara etnografi masyarakat pendukung sudah dalam kondisi sosial, budaya, dan ritualnya telah mengalami perubahan. Masyarakat berpikir, bertindak, bersikap, telah dipengaruhi oleh hal-hal yang bersifat kritis, rasional, lebih mengedepankan logika. Fenomena masyarakat tersebut tidak terlepaskan kemajuan pengetahuan, teknologi, dan informasi. Kemajuan tersebut berpengaruh pada pola pandang masyarakat pada kesenian sakral tersebut. Kemajuan tersebut tidak berpengaruh pada konsep, pola berpikir masyarakat yang tetap bersikap dan bertindak irasional (tradisi). Hal tersebut dipengaruhi oleh masih bisa dilihat keajaiban pada kesenian tersebut seperti: menari di atas bara api, ditusuk senjata tajam, masuk dalam kobaran api, dan peristiwa lainnya. Kesinan tersebut di zaman Hindu berkembang hampir di seluruh daerah di Bali. 
Secara subtantip mulai dari proses mendatangkan roh, kemudian menghegomoni tubuh dan masyarakat pendukung. Dengan persiapan sesaji, gambelan, nyanyian suci, dan ruang pementasan. Di beberapa tempat di Bali seperti: di Batubulan, Bona, Blabatuh Gianyar kesenian tersebut dimodivikasi, dipadukan dengan jenis tarian lain. Tujuan pengkemasan tersebut untuk hiburan yang diperuntukan dalam kebutuhan industri pariwisata. Peraturan pemerintah daerah provinsi Bali, Nomor 2 tahun 2012 tentang pariwisata budaya Bali, memungkinkan jenis tarian ini dikemas dengan tujuan kepentingan industri pariwisata. Hal tersebut pada prinsifnya pariwisata budaya merupakan salah satu bentuk pemanfaatan budaya untuk keperluan industri pariwisata. Produk dimaksudkan dalam hal ini mencakup produksi dan reproduksi kesenian sebagai bentuk hiburan. Douglas (1996:49) mengingatkan perubahan sosial budaya tidak sepenuhnya akibat dampak industri pariwisata seperti yang dialami pada tari sanghyang.

Sebelum masuk pariwisata masyarakat telah terjalin hubungan dengan budaya lain. Dalam industri budaya terjadi transformasi pemaknaan kebudayaan atau bagaimana kebudayaan dipandang, diperlakukan oleh pemilik modal dan pendukungnya. Awalnya tari sanghyang sebagai penanda atau jati diri dari masyarakat dari etnik Bali kemudian diposisikan sebagai modal atau sumber daya daya atau cultural capital (Bourdieu, 1998). Hal tersebut menyebabkan terjadinya perubahan pada masyarakat pendukungnya. Kemasan industri pariwisata seperti tari sanghyang hasil komudifikasi seperti di Desa Bono Blahbatuh, Batubulan, Gianyar sudah jarang dipentaskan, suatu saat akan kehilangan jejak tari sanghyang.

\section{Komunikasi Spritual}

Komunikasi diartikan sebagai suatu proses atau intraksi dua arah atau lebih dari seseorang, kelompok, masyarakat agar terjalain hubungan dengan orang lain. Komunikasi tidak didominasi oleh manusia, bisa juga antar binatang atau jenis mahluk lainnya. Pada manusia komunikasi dibangun atas kepentingan dari pihak-pihak tertentu dengan berbagai media. Media dalam komunikasi di artikan sebagai alat bantu agar tujuan-tujuan tersebut dengan mudah bisa dipahami dan dimengerti. Sedangkan spritual dimakanai sebagai kegiatan manusia dalam tataran rohaniah yang bersifat trasidensi, sulit dipahami, dimengerti oleh logika dan pikiran orang lain dalam bentuk tanda dan penanda. Hal tersebut dalam teori tanda Saussure, pemaknaan atas suatu tanda didekati dengan model dua sisi (dikotomis) dan bersifat konvensionla dengan memanfaatkan perangkat sosial yang ada dan pratik sosial. Sikap dan tingkah laku penari Sanghyang diposisikan sebagai penanda dari adanya roh dalam kesenian sakral tersebut. Ritual yang menyertai tarian sakral yang kerauhan (trace) petanda adanya keyakinan dan kepercayaan adanya kekuatan diluar diri manusia yang disebut roh. Keberadaan tarian Sanghyang oleh secara sosial religius adanya "kesadaran kolektif" menempatkan kesenian tersebut sebagai sesuatu yang "gaib".

Manusia modern menyangsikan adanya alam gaib, benda-benda gaoib, dan fenomena-fenomena gaib. Dalam ajaran agama dan spritual tidak lepas dari urusan yang bersifat spritual dan fenomena supranatural seperti pada Tari Sanghyang. Tampak adanya komunikasi, baik verbal maupun non verbal dari ekpresi wajah, gerak, sikap dan tubuh. Tetapi dalam komunikasi menggunakan katakata oleh antara manusia dengan roh yang ada dalam tubuh penari. Dalam kepercayaan dan keyakinan hindu, fenomena-fenomena adanya 
mahluk gaib yang baik dan buruk dikenal dan dipuja bersifat pamerih. Kemasukan, kerauhan (trance) adalah hal biasa dan sehari-hari kita dapat menyaksikan secara sengaja (roh-roh yang dipanggil maupun secara spontan, rohroh yang masuk secara tiba-tiba) ke perorangan atau massal. Dalam hal ini yang dimaksudkan komunikasi spritual mengandung makna rohaniah atau sesuatu terkait dengan karunia Tuhan (rohani) diberikan pada manusia dan spritual itu merupakan pancaran sifat-sifat ketuhanan. Komunikasi spritual sebagai komunikasi yang terjadi antara manusia dengan roh yang ada dalam tubuh penari Sanghyang bersifat keagamaan.

Tari Sanghyang dimana penarinya sedang "kerauhan (trance) kemasukan roh oleh pawang atau masyarakat diajak berbicara. Roh berbicara melalui media penari sanghyang terkait dengan maksud dan tujuan pementasan. Menurut penulis dialog antara manusia dengan roh membicarakan hal-hal bersifat diluar logika dan keyakinan penulis sebut dengan komunikasi spiritual. Komunikasi spritual dimaksudkan adalah adanya dialog kebatinan bersifat trasidensi antara manusia dengan roh, melalui media seperti tari sanghyang. Adanya komunikasi spritual tersebut diperkuat dengan penuturan "Mangku Pande" saat berdialog dengan roh agar tidak mengganggu anak-anak siswa/siswi SMK Swasta di Gianyar (wawancara, tgl 26 Desember, 2014).

\section{SIMPULAN}

Sejak zaman prasejarah sudah ada komunikasi spiritual antara manusia dengan roh hal tersebut terbukti adanya konsep artefak atau benda simbolis lainya digunakan sebagai media ritual (Lodra: 2013). Model komunikasi tersebut terus berlanjut pada zaman Bali Kuno, zaman Hindu sampai sekarang. Pada peradaban Hindu media komunikasi spritual dalam bentuk visual dan estetik seperti bentuk patung, arca, "jimat" dan jenis lainnya. Begitu juga "pawang" komunikasi spiritual di Bali seperti: pemangku, "dukun", dan "jero dasaran". Komunikasi spritual termasuk bagian dari ilmu pengetahuan yang bisa diajari dan dipelajari oleh semua orang. Jika tari "sanghyang" sampai punah bagian nilai budaya yang hilang. Untuk menjaga dan melestarikan komunikasi spritual perlu penstrukturan kembali tari sanghyang seperti yang dilakukan oleh penggiat industri pariwisata.

\section{UCAPAN TERIMA KASIH}

Di akhir tulisan ini, penulis sangat berterima kasih kepada pimpinan Universitas Negeri Surabaya, baik di tingkat fakultas maupun rektorat, yang telah memberikan kesempatan kepada penulis untuk melakukan penelitian tentang isu yang diangkat dalam tulisan ini, juga beberapa pihak dan informan yang terlibat dalam penggalian data dan informasi di dalamnya. Tidak ketinggalan, terima kasih juga penulis tujukan kepada Mitra Bestari dan Pengelola Jurnal Harmoni yang telah memberikan catatan dan saran untuk perbaikan tulisan ini, hingga bisa diterbitkan pada Jurnal Harmoni edisi kali ini. 


\section{DAFTAR PUSTAKA}

Ardana, IGusti. 2007. Pemberdayaan Kearipan Lokal Masyarakat Bali Dalam Menghadapi Budaya Global. Pustaka Tarukan Agung, Denpasar.

Ardika, Wayan. Pelestarian dan Pemanfaatan Tinggalan Arkeologi dalam mengembangkan pariwisata Budaya Bali.Denpasar: Program Studi Pariwisata Unud.

Ardika, Wayan dan Sutaba, Made.1989.Dinamisme Kebudayaan Bali.Denpasar:PT Upada Sastra.

Amir Piliang Yasraf. 2006.Dunia Yang Dilipat. Jalasutra.Yogyakarta.

Belharz, Peter. 2005. Teori-Teori Sosial.Yogyakarta: Pustaka Pelajar.

Benedict, Ruth. 1966. Pola-pola Kebudayaan. Jakarta: Dian rakyat.

Daeng, Hans J, 2000, Manusia, Kebudayaan dan Lingkungan, Pustaka Pelajar Yogyakarta.

Dharsono.2007. Estetika,Rekayasa sains, Bandung.

Dibia.2012. Taksu dalam seni dan Kehidupan. Bali Mangsi. Denpasar.

Geertz, Clifford. 1992. Tafsir Kebudayaan, Refleksi Budaya. Yokyakarta: Kanisius.

Gede Jaman. 1999. Rerajahan dalam Kehidupan Bali. Pramita Surabaya.

Geriya, I Wayan. 1989. Pariwisata dan Dinamika Kebudayaan Lokal, Nasional, Global. Denpasar: Upada Sastra. Faksas Unud.

1983. Pariwisata dan Segi-segi Sosial Budaya Masyarakat Bali. Denpasar:

Koentjaraningrat. 1997. Manusia dan Kebudayaan Indonesia. Jakrta: Djambatan Jakarta. 1996. Ritus Peralihan di Indonesia, Balai Pustaka.

Laeyendeker,L. 1991. Tata Perubahan dan Ketimpangan. Jakarta: Gramedia Pustaka Utama. Lodra, Nyoman, 2014, Roh Etnis Bali dalam Kriya Perak Suarti, Denpasar, Bali Mangsi

Sastrodiwiryo, Soegianto, 2010, Perjalanan Danghyang Niratha, cetakan ke 5, BP, Denpasar.

Sri Srimad A.C. Bhaktivedanta Swami Prabupada, Di Luar Kelahiran dan Kematian, The Bhaktivedanta Book Trust.

Soejono. 1977, Sistem-sistem penguburan pada akhir masa prasejarah di Bali, Jakarta.

Triguna Yudha I.B.G, 2003, Estetika Hindu dan Pembangunan Bali, Program Magister UNHI Denpasar.

Hanna, Judith Lynne. 1987. To Dance is Human: A Theory of Nonverbal Communication. Chicago: University of Chicago Press.

Herbert, David.2011. Mediatization, religion and aesthetics. Paper prepared for a RESEP seminar, Kritiansand,January 7.

Hoving, Mate Kristi. 2004. "Dancing on Holy Ground. Embodied Expressions". Mater thesis

HARMONI | Juli-Desember 2017 
in intercontextual theology, Facullty of Theology.Oslo: University Oslo.

Kvale, Stenar.1996. Interviews: An Introduction to Qualitative Researh Interviewing. Thousand Oaks: Sage.

LaMothe, Kimerer L. 2004. Between Dancing and Writing. He Practice of Religious Studies. New York: Fodham University Press.

La Taena, dkk.2016. The Cultural Tradision of "Falia" in Preserving forest bay ethnic. Journal of Sustainable development: Vol.9.No. 5: 2016, Published bay Canadian center of Science and Education.

Lundvall,Suzanne and Ninitha Maivorsdotter.2010." Aesthetic aspects ini meaning makingan explorative study of dance education in a PETE program". Design for Learning 3 (1-2); 30-40.

Lovland, Anne and Pal Repstad. 2011." How to play the emotional card. Studying the aestheticisation of religion." Paper presented at a UiA/RESEP research seminar,Bo Norway,September 1-2.

Meleau-Ponty, Maurice. 1994.Kroppens fenomenologi Translated to Danish by Bjorn Nake. Oslo: Pax.

Stephan Bongard. 2010. "Shall we dance? An exploration of the perceived benefits of dancing on well-being. Arts\& Heakth (2): 149-163.

Postholm, May Britt. 2005. Kualitativ metode: en innforing med fokus pa fenomenologi, etnografi og kasusstudier. Oslo: universitetsforlaget.

Royce, Anya Peterson.2002.The Anthropology of Dance. Hampshire: Dance Books. 